\title{
Wnt3a upregulates prostaglandin F2 $\alpha$-stimulated vascular endothelial growth factor synthesis in osteoblasts
}

\author{
AKIRA KONDO $^{1,2}$, HARUHIKO TOKUDA $^{1,3}$, JUN MIZUTANI ${ }^{2}$, RIE MATSUSHIMA-NISHIWAKI $^{1}$, \\ OSAMU KOZAWA ${ }^{1}$ and TAKANOBU OTSUKA ${ }^{2}$ \\ ${ }^{1}$ Department of Pharmacology, Gifu University Graduate School of Medicine, Gifu 501-1194; \\ ${ }^{2}$ Department of Orthopedic Surgery, Nagoya City University Graduate School of Medical Sciences, Nagoya 467-8601; \\ ${ }^{3}$ Department of Clinical Laboratory, National Center for Geriatrics and Gerontology, Obu 474-8511, Japan
}

Received February 3, 2012; Accepted April 26, 2012

DOI: $10.3892 / \mathrm{mmr} .2012 .916$

\begin{abstract}
It is known that Wnt3a affects bone metabolism via the canonical Wnt/ $\beta$-catenin signaling pathway. We have previously shown that prostaglandin F2 $\alpha(\mathrm{PGF} 2 \alpha)$ stimulates the synthesis of vascular endothelial growth factor (VEGF) and interleukin-6 (IL-6) via mitogen-activated protein (MAP) kinases, including p44/p42 MAP kinase, p38 MAP kinase and stress-activated protein kinase (SAPK)/c-Jun N-terminal kinase (JNK) in osteoblast-like MC3T3-E1 cells. In the present study, we investigated the effects of Wnt3a on the synthesis of VEGF or IL- 6 stimulated by PGF2 $\alpha$ in MC3T3-E1 cells using an ELISA kit and various antibodies. Cells were cultured and pretreated with various doses of Wnt3a or SB216763, an inhibitor of glycogen synthase kinase $3 \beta$, prior to western blotting. Wnt3a significantly enhanced the PGF2 $\alpha$-stimulated VEGF release but had little effect on the PGF2 $\alpha$-stimulated IL-6 release. SB216763 markedly amplified the PGF2 $\alpha$ stimulated VEGF release without affecting the IL- 6 release, similar to Wnt3a. Wnt3a failed to affect the PGF2 $\alpha$-induced phosphorylation of p44/p42 MAP kinase, p38 MAP kinase or SAPK/JNK. These results strongly suggest that Wnt3a upregulates VEGF synthesis stimulated by PGF2 $\alpha$ via activation of the canonical pathway in osteoblasts without affecting IL-6 synthesis.
\end{abstract}

\section{Introduction}

Prostaglandins (PGs) play significant roles as autacoids of bone metabolism $(1,2)$. It is widely acknowledged that the metabolism of bone tissue requires the concerted actions of bone formation and bone resorption, which are regulated by osteoblasts and osteoclasts, respectively (3). In bone metabolism,

Correspondence to: Dr Haruhiko Tokuda, Department of Clinical Laboratory, National Center for Geriatrics and Gerontology, Obu 474-8511, Aichi Prefecture, Japan

E-mail: tokuda@ncgg.go.jp

Key words: prostaglandin F2 $\alpha$, vascular endothelial growth factor, interleukin-6, Wnt3a, osteoblast
PGF2 $\alpha$ is known to act as a potent bone modulator via specific receptors (FP) on osteoblasts $(1,2)$. It has been reported that PGF2 $\alpha$ stimulates the proliferation of osteoblasts and inhibits their differentiation (2). In our previous studies $(4,5)$, we revealed that PGF $2 \alpha$ induces the activation of protein kinase $\mathrm{C}$ via phosphoinositide-hydrolyzing phospholipase $\mathrm{C}$ and phosphatidylcholine-hydrolyzing phospholipase D in osteoblast-like MC3T3-E1 cells. However, PGF2 $\alpha$ reportedly stimulates the synthesis of vascular endothelial growth factor (VEGF) and interleukin-6 (IL-6) in osteoblasts $(2,6)$ and these bioactive substances, released from osteoblasts, are known to function as potent modulators in bone metabolism. However, the exact mechanism behind the PGF $2 \alpha$-stimulated synthesis in osteoblasts has yet to be clarified.

VEGF is a strong mitogen which has a high specificity for vascular endothelial cells (7) and is synthesized and secreted by a range of cell types. The protein increases capillary permeability and stimulates endothelial cells to proliferate (7). During bone remodeling, capillary endothelial cells provide microvasculature. The activities of osteoblasts, osteoclasts and capillary endothelial cells are known to be closely associated and to regulate bone metabolism (8). It is thought that these cell types interact via humoral factors and cell-to-cell contact. A previous study used a co-culture model of osteoblasts and endothelial cells to reveal that VEGF is crucial for the differentiation of osteoblasts (9). It is widely acknowledged that VEGF is a significant regulator of the growth and repair of bone. In our previous studies $(6,10)$, we revealed that in osteoblast-like MC3T3-E1 cells, PGF2 $\alpha$-stimulated VEGF synthesis is positively regulated by p44/p42 mitogen-activated protein (MAP) kinase, p38 MAP kinase and stress-activated protein kinase/cJun N-terminal kinase (SAPK/JNK), which are members of the MAP kinase superfamily (11). By contrast, IL-6 is a multifunctional cytokine that has crucial effects on a wide range of functions, including the promotion of B-cell differentiation and T-cell activation and induction of acute phase proteins (12). In bone metabolism, IL-6 is generally known to stimulate bone resorption and promote osteoclast formation (13). It has been reported that potent bone resorptive agents, including tumor necrosis factor- $\alpha$ and IL-1, stimulate IL-6 synthesis in osteoblasts (13). Accumulating evidence suggests that IL-6 secreted from osteoblasts is crucial as a downstream effector of bone 
resorptive agents in bone metabolism. We previously demonstrated that PGF2 $\alpha$ stimulates IL-6 synthesis via the activation of protein kinase $\mathrm{C}$ (14).

Wnts are secreted glycoproteins that regulate early embryonic development and cell proliferation, differentiation and survival $(15,16)$. $\beta$-catenin is one of the key downstream effectors in the Wnt pathway. In the canonical Wnt/ $\beta$-catenin signaling pathway (15), Wnts bind to Frizzled receptors and the low-density lipoprotein receptor-related protein 5 or 6 (LRP5/6) in vertebrates $(16,17)$. This complex leads to the phosphorylation and inactivation of glycogen synthase kinase $3 \beta$ (GSK3 $\beta$ ), which destabilizes $\beta$-catenin and suppresses the accumulation of $\beta$-catenin in the nucleus (15). In bone tissue, it has been shown that loss or gain of function mutations in LRP-5 are associated with osteoporosis-pseudoglioma syndrome or a high bone density syndrome, respectively, in humans (17). Moreover, the genetic deletion of $\beta$-catenin from early osteoprogenitors results in a lack of mature osteoblasts in the mouse embryo (17), whereas the forced activation of $\beta$-catenin greatly enhances osteogenesis (18). Accumulating evidence concerning the roles of molecules downstream of LRP5, including GSK3 $\beta$ and $\beta$-catenin, indicates that the Wnt signaling pathway is pivotal in bone metabolism, especially bone formation $(17,19,20)$. The exact roles of the Wnt/ $\beta$-catenin signaling pathway in osteoblasts have yet to be elucidated, although osteoblasts have been reported to produce Wnt proteins (17). Among the Wnt-ligands, it has been shown that Wnt3a mainly activates the canonical pathway in osteoblasts (21). In the present study, we investigated whether Wnt3a affects the PGF2 $\alpha$-stimulated synthesis of VEGF and IL-6 in osteoblast-like MC3T3-E1 cells. We showed that Wnt3a enhances PGF $2 \alpha$-stimulated VEGF synthesis via the canonical Wnt/ $\beta$-catenin pathway in these cells while Wnt3a had little effect on the IL-6 synthesis.

\section{Materials and methods}

Materials. PGF2 $\alpha$, Wnt3a and the mouse VEGF and IL-6 enzyme-linked immunosorbent assay (ELISA) kits were purchased from R\&D Systems, Inc. (Minneapolis, MN, USA). SB216763 was obtained from Calbiochem-Novabiochem Co. (La Jolla, CA, USA). Phospho-specific p44/p42 MAP kinase antibodies, p44/p42 MAP kinase antibodies, phospho-specific p38 MAP kinase antibodies, p38 MAP kinase antibodies, phospho-specific SAPK/JNK antibodies and SAPK/JNK antibodies were purchased from Cell Signalling Technology, Inc. (Beverly, MA, USA). The ECL western blotting detection system was purchased from GE Healthcare UK Ltd. (Buckinghamshire, UK). SB216763 was dissolved in dimethyl sulfoxide. Other materials and chemicals were obtained from commercial sources. The maximum concentration of dimethyl sulfoxide was $0.1 \%$, which did not affect the ELISA or western blot analysis.

Cell culture. The cloned osteoblast-like MC3T3-E1 cells, which are derived from newborn mouse calvaria (22), were maintained as previously described (23). Briefly, the cells were cultured in $\alpha$-minimum essential medium ( $\alpha$-MEM) containing $10 \%$ fetal calf serum (FCS) at $37^{\circ} \mathrm{C}$ in a humidified atmosphere of $5 \% \mathrm{CO}_{2} / 95 \%$ air. The cells were seeded in 35-mm diameter dishes $\left(5 \times 10^{4}\right.$ cells/dish) or 90-mm diameter dishes $\left(20 \times 10^{4}\right.$ cells/dish) in $\alpha$-MEM containing $10 \%$ FCS. After 5 days, the medium was changed to $\alpha$-MEM containing $0.3 \%$ FCS and the cells were incubated for $48 \mathrm{~h}$. The cells were then used for subsequent experiments.

Assay for VEGF and IL-6. The cultured cells were pretreated with various doses of Wnt3a or SB216763 for $60 \mathrm{~min}$ and then stimulated with $10 \mathrm{mM}$ PGF $2 \alpha$ or vehicle in $\alpha$-MEM containing $0.3 \%$ FCS for the indicated periods. The conditioned medium was then collected and VEGF or IL-6 in the medium was measured using the mouse VEGF or IL-6 ELISA kit according to the manufacturer's instructions. The absorbance of the ELISA samples was measured at $450 \mathrm{~nm}$ using EL 340 Bio Kinetic Reader (Bio-Tek Instruments, Inc., Winooski, VT, USA).

Western blot analysis. Western blot analysis was performed as previously described (24). In brief, the cultured cells were pretreated with various doses of Wnt3a for $60 \mathrm{~min}$ and stimulated with $10 \mathrm{mM}$ PGF $2 \alpha$ or vehicle in $\alpha$-MEM containing $0.3 \%$ FCS for the indicated periods. The cells were washed twice with phosphate-buffered saline and then lysed, homogenized and sonicated in a lysis buffer containing $62.5 \mathrm{mM}$ Tris $/ \mathrm{HCl}$; $\mathrm{pH} 6.8,3 \%$ sodium dodecyl sulfate (SDS), $50 \mathrm{mM}$ dithiothreitol and $10 \%$ glycerol. SDS-polyacrylamide gel electrophoresis (PAGE) was performed as described by Laemmli (25) using a $10 \%$ polyacrylamide gel. The protein $(10 \mathrm{mg})$ was fractionated and transferred onto an Immun-Blot PVDF membrane (Bio-Rad, Hercules, CA, USA). The membranes were blocked with $5 \%$ fat-free dry milk in Tris-buffered saline-Tween (TBS-T; $20 \mathrm{mM}$ Tris/HCl, pH 7.6, $137 \mathrm{mM} \mathrm{NaCl}, 0.1 \%$ Tween-20) for $2 \mathrm{~h}$ prior to incubation with the primary antibodies. The rabbit polyclonal phospho-specific p44/p42 MAP kinase antibodies, p44/p42 MAP kinase antibodies, phospho-specific SAPK/JNK antibodies, SAPK/JNK antibodies, phospho-specific p38 MAP kinase antibodies or p38 MAP kinase antibodies were used as primary antibodies. Peroxidase-labeled antibodies raised in goat against rabbit IgG were used as secondary antibodies. The primary and secondary antibodies were diluted at 1:1,000 with $5 \%$ fat-free dry milk in TBS-T. Peroxidase activity on the membrane was visualized on X-ray film by means of the ECL western blotting detection system.

Statistical analysis. The data were analyzed by ANOVA followed by the Bonferroni method for multiple comparisons between pairs and $\mathrm{P}<0.05$ was considered to indicate a statistically significant result. Data were presented as the mean \pm SEM of triplicate determinations. Each experiment was repeated three times with similar results.

\section{Results}

Effect of Wnt $3 a$ on the PGF $2 \alpha$-stimulated VEGF release in osteoblast-like MC3T3-E1 cells. Since we previously showed that PGF $2 \alpha$ significantly stimulates VEGF synthesis in osteoblast-like MC3T3-E1 cells (6), we first examined the effect of Wnt3a on VEGF release induced by PGF $2 \alpha$ in these cells. Wnt3a significantly enhanced the PGF $2 \alpha$-induced VEGF release (Fig. 1). Amplification by Wnt3a was dose-dependent 


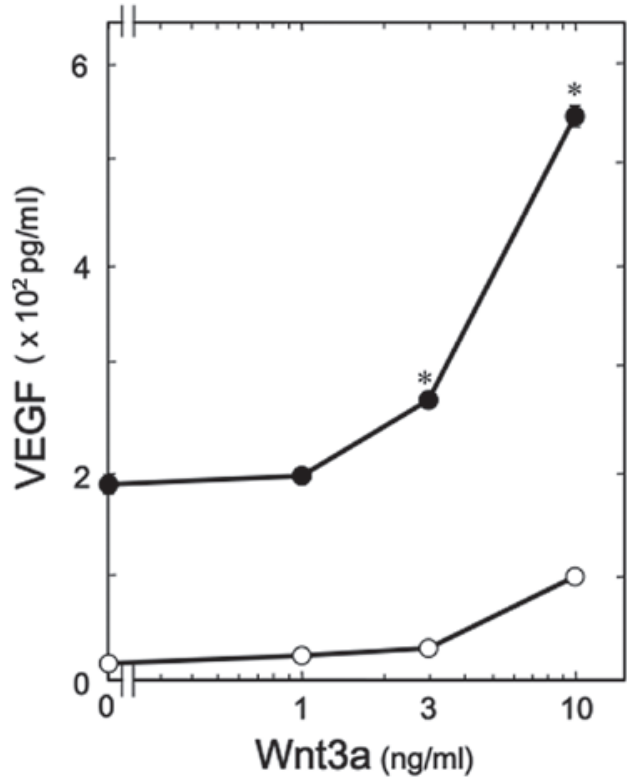

Figure 1. Effect of Wnt3a on the PGF2 $\alpha$-stimulated VEGF release in MC3T3-E1 cells. The cultured cells were pretreated with various doses of Wnt3a for $60 \mathrm{~min}$ and then stimulated by $10 \mathrm{mM}$ PGF2 $\alpha(\bullet)$ or vehicle (O) for $48 \mathrm{~h}$. Each value is the mean \pm SEM of triplicate determinations. Similar results were obtained with two additional and different cell preparations. ${ }^{*} \mathrm{P}<0.05$, compared with the value of PGF $2 \alpha$ alone. PGF $2 \alpha$, prostaglandin F2 $\alpha$; VEGF, vascular endothelial growth factor.

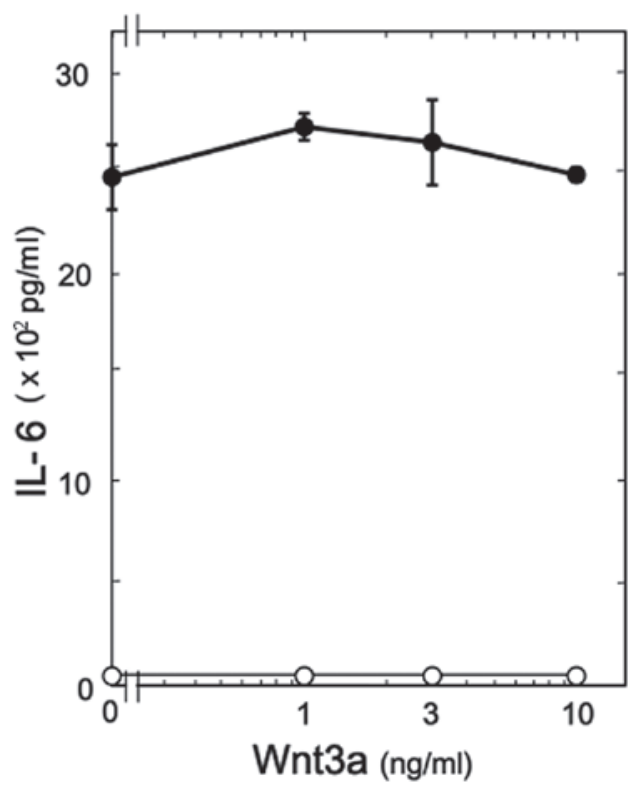

Figure 2. Effect of Wnt3a on the PGF2 $\alpha$-stimulated interleukin-6 release in MC3T3-E1 cells. The cultured cells were pretreated with various doses of Wnt3a for $60 \mathrm{~min}$ and then stimulated by $10 \mathrm{mM}$ PGF2 $\alpha(\bullet)$ or vehicle (O) for $48 \mathrm{~h}$. Each value is the mean \pm SEM of triplicate determinations. Similar results were obtained with two additional and different cell preparations PGF2 $\alpha$, prostaglandin F2 $\alpha$; IL-6, interleukin-6.

at doses between 1 and $10 \mathrm{ng} / \mathrm{ml}$. A dose of $10 \mathrm{ng} / \mathrm{ml} \mathrm{Wnt3a}$ resulted in a $\sim 160 \%$ increase in the PGF2 $\alpha$ effect.

Effect of Wnt $3 a$ on the PGF $2 \alpha$-stimulated $I L-6$ release in osteoblast-like MC3T3-E1 cells. Previously, we demonstrated

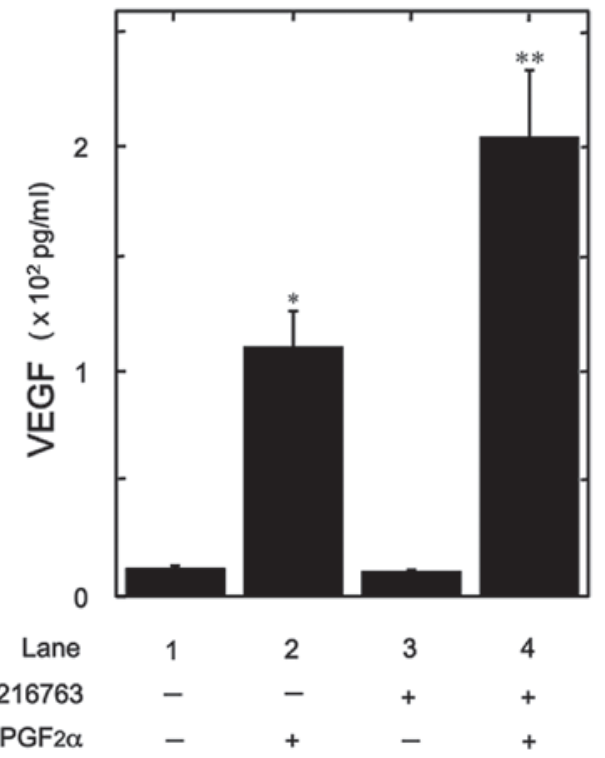

Figure 3. Effect of SB216763 on the PGF2 $\alpha$-stimulated VEGF release in MC3T3-E1 cells. The cultured cells were pretreated with 10 mM SB216763 or vehicle for $60 \mathrm{~min}$ and stimulated with $10 \mathrm{mM}$ PGF $2 \alpha$ or vehicle for $48 \mathrm{~h}$ Each value is the mean \pm SEM of triplicate determinations. Similar results were obtained with two additional and different cell preparations. ${ }^{*} \mathrm{P}<0.05$, compared with the value of the control. ${ }^{* *} \mathrm{P}<0.05$, compared with the value of PGF $2 \alpha$ alone. PGF $2 \alpha$, prostaglandin F $2 \alpha$; VEGF, vascular endothelial growth factor.

that PGF2 $\alpha$ stimulates IL-6 synthesis in osteoblast-like MC3T3-E1 cells (14). In the present study, we examined the effect of Wnt3a on IL- 6 release induced by PGF $2 \alpha$ in these cells. However, Wnt3a, which alone had little effect on the IL-6 levels, did not affect the PGF2 $\alpha$-induced IL-6 release (Fig. 2).

Effects of SB216763 on the PGF2 $\alpha$-stimulated release of VEGF or IL-6 in MC3T3-El cells. In the canonical Wnt/ $\beta$-catenin pathway, Wnt stimulation inhibits the GSK $3 \beta$ activity that otherwise phosphorylates $\beta$-catenin and induces its degradation $(15,16)$. It has been reported that $\beta$-catenin accumulation is stimulated by an inhibitor of GSK3 $\beta$ as well as Wnt in pre-osteoblast CIMC-4 cells (26). Therefore, we examined the effect of SB216763, an inhibitor of GSK3 $\beta$ (27), on the PGF2 $\alpha$-induced VEGF release. SB216763 markedly potentiated the VEGF release (Fig. 3). A dose of $10 \mathrm{mM}$ of SB216763 resulted in a $100 \%$ increase in the PGF2 $\alpha$-effect.

We also examined the effect of SB216763 on the PGF2 $\alpha$ induced IL-6 release in MC3T3-E1 cells. However, SB216763 had little effect on the PGF2 $\alpha$-induced IL-6 release (Fig. 4).

Effects of Wnt3a on the phosphorylation of p44/p42 MAP kinase, SAPK/JNK and 38 MAP kinase induced by PGF $2 \alpha$ in MC3T3-E1 cells. In a previous study, we showed that $\mathrm{p} 44 / \mathrm{p} 42$ MAP kinase, p38 MAP kinase and SAPK/JNK are involved in the PGF2 $\alpha$-stimulated VEGF synthesis in osteoblast-like MC3T3-E1 cells $(6,10)$. Therefore, to investigate whether the amplifying effect of Wnt3a on the VEGF synthesis is dependent on the MAP kinase pathway in MC3T3-E1 cells, we examined the effects of Wnt $3 \mathrm{a}$ on the PGF $2 \alpha$-induced phosphorylation of p44/p42 MAP kinase, p38 MAP kinase and SAPK/JNK. However, Wnt3a hardly affected the PGF2 $\alpha$-stimulated 


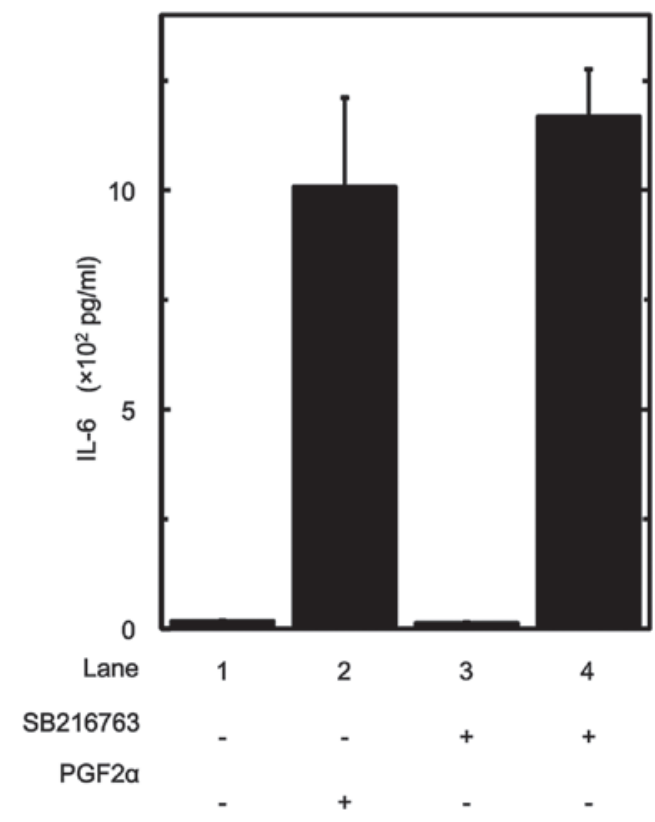

Figure 4. Effect of SB216763 on the PGF2 $\alpha$-stimulated interleukin-6 release in MC3T3-E1 cells. The cultured cells were pretreated with $10 \mathrm{mM} \mathrm{SB} 216763$ or vehicle for $60 \mathrm{~min}$ and stimulated with $10 \mathrm{mM} \mathrm{PGF} 2 \alpha$ or vehicle for $48 \mathrm{~h}$ Each value is the mean \pm SEM of triplicate determinations. Similar results were obtained with two additional and different cell preparations. PGF2 $\alpha$, prostaglandin F2 $\alpha$; IL-6, interleukin-6.

phosphorylation of p44/p42 MAP kinase at doses between 10 and $50 \mathrm{ng} / \mathrm{ml}$ (Fig. 5A). Furthermore, Wnt3a had little effect on the phosphorylation of p38 MAP kinase (Fig. 5B) or SAPK/ JNK (Fig. 5C) by PGF2 $\alpha$ at doses between 10 and $50 \mathrm{ng} / \mathrm{ml}$.

\section{Discussion}

In the present study, we demonstrated that Wnt3a significantly enhanced VEGF synthesis stimulated by PGF2 $\alpha$ in osteoblast-like MC3T3-E1 cells. However, the PGF2 $\alpha$-stimulated IL-6 synthesis was not affected by Wnt3a in these cells. The activation of the canonical pathway, which is well known as a major signaling pathway involving Wnt, causes the accumulation of $\beta$-catenin in the nucleus through the inactivation of GSK3 $\beta$, which otherwise induces the degradation of $\beta$-catenin $(15,28)$. It has been reported that $\mathrm{Wnt} 3 \mathrm{a}$ increases $\beta$-catenin levels in osteoblasts (28). We confirmed that Wnt3a upregulated the protein levels of $\beta$-catenin in a time-dependent manner in MC3T3-E1 cells. We also showed that SB216763, a specific GSK3 $\beta$ inhibitor (27), markedly enhanced the VEGF synthesis stimulated by PGF $2 \alpha$ as well as Wnt3a in MC3T3-E1 cells. In addition, SB216763 had little effect on the PGF2 $\alpha$-stimulated IL-6 synthesis, similar to Wnt3a. Therefore, our findings suggest that Wnt3a upregulates PGF2 $\alpha$-stimulated VEGF synthesis via the canonical $\mathrm{Wnt} / \beta$-catenin pathway in osteoblast-like MC3T3-E1 cells.

It is generally known that members of the MAP kinase superfamily, including p44/p42 MAP kinase, p38 MAP kinase and SAPK/JNK, are central elements used by mammalian cells to transmit various extracellular messages (11). With regard to VEGF synthesis in osteoblasts, we have previously reported that the activation of three major MAP kinases, p44/

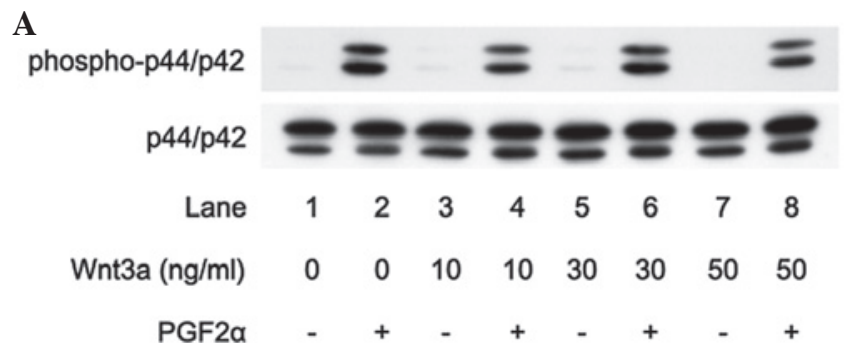

B
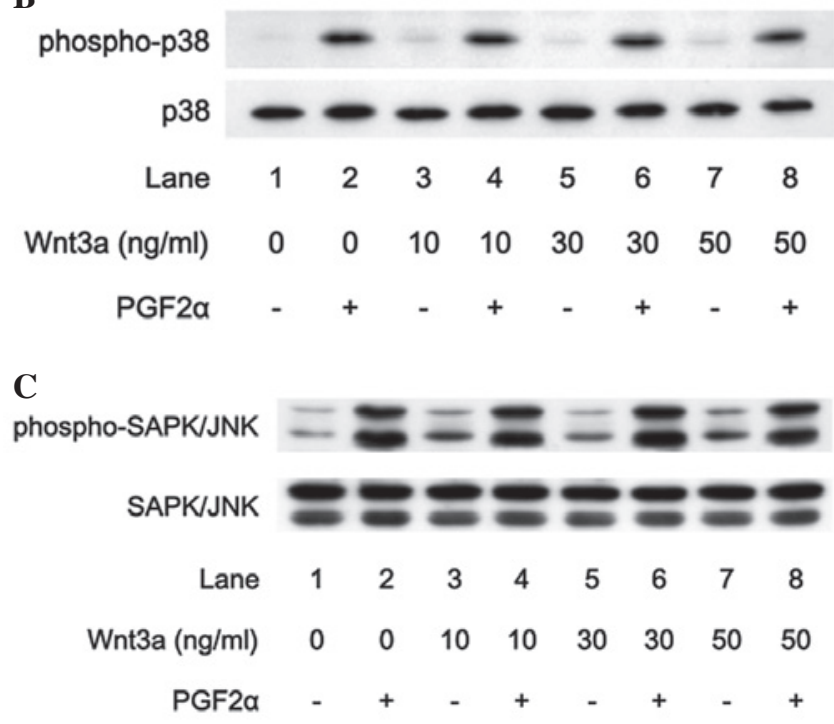

Figure 5. Effects of Wnt3a on the PGF2 $\alpha$-induced phosphorylation of (A) p44/ p42 MAP kinase, (B) p38 MAP kinase and (C) SAPK/JNK in MC3T3-E1 cells. The cultured cells were pretreated with various doses of Wnt3a for $60 \mathrm{~min}$ and stimulated with $10 \mathrm{mM}$ PGF $2 \alpha$ or vehicle for $20 \mathrm{~min}$. The cell extracts were then subjected to SDS-PAGE with subsequent western blot analysis with antibodies against (A) phospho-specific p44/p42 MAP kinase and p44/p42 MAP kinase, (B) phospho-specific p38 MAP kinase and p38 MAP kinase and (C) phospho-specific SAPK/JNK and SAPK/JNK. Similar results were obtained with two additional and different cell preparations in each assay. PGF $2 \alpha$, prostaglandin F2 $\alpha$; MAP, mitogen-activated protein; SAPK/JNK, stress-activated protein kinase/c-Jun N-terminal kinase; SDS-PAGE, sodium dodecyl sulfate-polyacrylamide gel electrophoresis.

p42 MAP kinase, p38 MAP kinase and SAPK/JNK, positively regulates PGF2 $\alpha$-stimulated VEGF synthesis in osteoblast-like MC3T3-E1 cells $(6,10)$. Thus, we investigated the correlation between the Wnt pathway and the MAP kinase pathway in the PGF2 $\alpha$-stimulated VEGF synthesis in MC3T3-E1 cells. However, Wnt3a did not increase the PGF2 $\alpha$-induced phosphorylation levels of p44/p42 MAP kinase. In addition, the PGF $2 \alpha$-induced phosphorylation levels of p38 MAP kinase and SAPK/JNK were not affected by Wnt3a. Based on these findings, it appears to be unlikely that Wnt3a affects PGF $2 \alpha$-stimulated VEGF synthesis via the modulation of p44/p42 MAP kinase, p38 MAP kinase or SAPK/JNK in osteoblast-like MC3T3-E1 cells. Therefore, it is likely that Wnt3a modulates PGF2 $\alpha$-induced VEGF synthesis at a point downstream of the MAP kinases or that the effect of Wnt3a is exerted via the modulation of other signaling pathways.

In bone tissue, the expansion of a capillary network providing microvasculature is an essential process in bone remodeling (9). Since VEGF is a specific mitogen of vascular endothelial cells (7), VEGF released from osteoblasts acts as 
a significant intercellular mediator between osteoblasts and vascular endothelial cells. Moreover, VEGF is reportedly involved in trabecular bone formation and the expansion of the hypertrophic chondrocyte zone in the epiphyseal growth plate of mice (29), indicating the significance of VEGF in bone metabolism. However, bone is capable of regenerating and repairing itself after suffering from damage such as fractures. It is known that the localized activation of signal cascades is required for bone regeneration and fracture healing (30). Moreover, the Wnt/ $\beta$-catenin signaling pathway is known to play an anabolic role in bone metabolism, leading to bone formation (17). The Wnt signaling pathway has been reported to be activated and induce bone regeneration during bone fracture repair, resulting in the increase of bone mass (30). In the present study, we demonstrated that Wnt3a enhanced the PGF2 $\alpha$-stimulated VEGF synthesis without affecting the synthesis of IL-6, a potent bone resorptive agent (13), in osteoblast-like MC3T3-E1 cells. Taking all our results into account, it is probable that Wnt3a-enhanced VEGF synthesis in osteoblasts is crucial in the physiological process of skeletal maintenance, including bone remodeling and fracture healing, by upregulating the proliferation of capillary endothelial cells. These findings lead us to speculate that the effect of Wnt in bone metabolism is mediated, at least in part, by VEGF release from osteoblasts. Further investigation is necessary to clarify the exact mechanism of the Wnt pathway in osteoblasts.

In conclusion, our results strongly suggest that Wnt3a amplifies PGF $2 \alpha$-stimulated VEGF synthesis via the activation of the canonical Wnt/ $\beta$-catenin signaling pathway in osteoblasts.

\section{Acknowledgements}

We are grateful to Yoko Kawamura and Emiko Fuseya for their skillful technical assistance. This investigation was supported in part by a Grant-in-Aid for Scientific Research (19591042) from the Ministry of Education, Science, Sports and Culture of Japan, the Foundation for Growth Science, the Research Grants for Longevity Sciences (21A-1, 21A-4 and 21A-22) the Ministry of Health, Labour and Welfare of Japan.

\section{References}

1. Pilbeam CC, Harrison JR and Raisz LG: Prostaglandins and bone metabolism. In: Principles of Bone Biology. Bilezikian JP, Raisz LG and Rodan GA (eds). Academic press, San Diego, pp715-728, 1996.

2. Hikiji H, Takato T, Shimizu T and Ishii S: The roles of prostanoids, leukotrienes, and platelet-activating factor in bone metabolism and disease. Prog Lipid Res 47: 107-126, 2008

3. Karsenty G and Wagner EF: Reaching a genetic and molecular understanding of skeletal development. Dev Cell 2: 389-406, 2002

4. Miwa M, Tokuda H, Tsushita K, Kotoyori J, Takahashi Y, Ozaki N, Kozawa O and Oiso Y: Involvement of pertussis-toxinsensitive GTP-binding protein in prostaglandin F2 $\alpha$-induced phosphoinositide hydrolysis in osteoblast-like cells. Biochem Biophys Res Commun 171: 1229-1235, 1990.

5. Kozawa O, Suzuki A, Kotoyori J, Tokuda H, Watanabe Y, Ito Y and Oiso Y: Prostaglandin F $\alpha$-activates phospholipase D independently from activation of protein kinase $\mathrm{C}$ in osteoblast-like cells. J Cell Biochem 55: 373-379, 1994.

6. Tokuda H, Harada A, Hirade K, Matsuno H, Ito H, Kato K, Oiso Y and Kozawa O: Incadronate amplifies prostagland in F $2 \alpha$-induced vascular endothelial growth factor in osteoblasts: enhancement of MAP kinase activity. J Biol Chem 278: 18930-18937, 2003.

7. Ferrara N: Vascular endothelial growth factor: basic science and clinical progress. Endoc Rev 25: 581-611, 2004.
8. Erlebacher A, Filvaroff EH, Gitelman SE and Derynck R: Toward a molecular understanding of skeletal development. Cell 80: 371-378, 1995

9. Grellier M, Ferreira-Tojais N, Bourget C, Bareille R, Guillemot F and Amédée J: Role of vascular endothelial growth factor in the communication between human osteoprogenitors and endothelial cells. J Cell Biochem 106: 390-398, 2009.

10. Tokuda H, Takai S, Matsushima-Nishiwaki R, Akamatsu S, Hanai Y, Hosoi T, Harada A, Ohta T and Kozawa O: (-)-epigallocatechin gallate enhances prostaglandin F2 $\alpha$-induced VEGF synthesis via up-regulating SAPK/JNK activation in osteoblasts. J Cell Biochem 100: 1146-1153, 2007.

11. Kyriakis JM and Avruch J: Mammalian mitogen-activated protein kinase signal transduction pathways activated by stress and inflammation. Physiol Rev 81: 807-869, 2001.

12. Kishimoto T: Interleukin-6: from basic science to medicine - 40 years in immunology. Annu Rev Immunol 23: 1-21, 2005.

13. Kwan Tat S, Padrines M, Théoleyre S, Heymann D and Fortun Y: IL-6, RANKL, TNF-alpha/IL-1: interrelations in bone resorption pathophysiology. Cytokine Growth Factor Rev 15: 49-60, 2004.

14. Kozawa O, Suzuki A, Tokuda H and Uematsu T: Prostaglandin F2 $\alpha$ stimulates interleukin- 6 via activation of PKC in osteoblastlike cells. Am J Physiol 272: E208-E211, 1997.

15. Moon RT, Bowerman B, Boutros M and Perrimon N: The promise and perils of Wnt signalling through $\beta$-catenin. Science 296: 1644-1646, 2002.

16. van Amerongen $R$ and Nusse R: Towards an integrated view of Wnt signalling in development. Development 136: 3205-3214, 2009.

17. Milat $\mathrm{F}$ and $\mathrm{Ng} \mathrm{KW}$ : Is Wnt signalling the final common pathway leading to bone formation? Mol Cell Endocrinol 310: 52-62, 2009.

18. Rodda SJ and McMahon AP: Distinct roles for hedgehog and canonical Wnt signalling in specification, differentiation and maintenance of osteoblast progenitors. Development 133: 3231-3244, 2006.

19. Hu H, Hilton MJ, Tu X, Yu K, Ornitz DM and Long F: Sequential roles of Hedgehog and Wnt signalling in osteoblast development. Development 132: 49-60, 2005.

20. Krishnan V, Bryant HU and Macdougald OA: Regulation of bone mass by Wnt signalling. J Clin Invest 116: 1202-1209, 2006.

21. Almeida M, Han L, Bellido T, Manolagas SC and Kousteni S: Wnt proteins prevent apoptosis of both uncommitted osteoblast progenitors and differentiated osteoblasts by $\beta$-catenindependent and -independent signalling cascades involving Src/ ERK and phosphatidylinositol 3-kinase/AKT. J Biol Chem 280: 41342-41351, 2005.

22. Sudo H, Kodama H, Amagai Y, Yamamoto S and Kasai S: In vitro differentiation and calcification in a new clonal osteogenic cell line derived from newborn mouse calvaria. J Cell Biol 96: 191-198, 1983.

23. Kozawa O, Tokuda H, Miwa M, Kotoyori J and Oiso Y: Cross-talk regulation between cyclic AMP production and phosphoinositide hydrolysis induced by prostaglandin E2 in osteoblast-like cells. Exp Cell Res 198: 130-134, 1992.

24. Kato K, Ito H, Hasegawa K, Inaguma Y, Kozawa O and Asano T: Modulation of the stress-induced synthesis of hsp27 and $\alpha \mathrm{B}$-crystallin by cyclic AMP in C6 rat glioma cells. J Neurochem 66: 946-950, 1996

25. Laemmli UK: Cleavage of structural proteins during the assembly of the head of bacteriophage T4. Nature 227: 680-685, 1970.

26. Case N, Ma M, Sen B, Xie Z, Gross TS and Rubin J: $\beta$-catenin levels influence rapid mechanical responses in osteoblasts. J Biol Chem 283: 29196-29205, 2008.

27. Carmichael J, Sugars KL, Bao YP and Rubinsztein DC: Glycogen synthase kinase- $3 \beta$ inhibitors prevent cellular polyglutamine toxicity caused by the Huntington's disease mutation. J Biol Chem 277: 33791-33798, 2002.

28. Chung YS, Baylink DJ, Srivastava AK, Amaar Y, Tapia B, Kasukawa Y and Mohan S: Effects of secreted frizzled-related protein 3 on osteoblasts in vitro. J Bone Miner Res 19: 1395-1402, 2004.

29. Gerber HP, Vu TH, Ryan AM, Kowalski J, Werb Z and Ferrara N: VEGF couples hypertrophic cartilage remodeling, ossification and angiogenesis during endochondral bone formation. Nature Med 5: 623-628, 1999.

30. Secreto FJ, Hoeppner LH and Westendorf JJ: Wnt signalling during fracture repair. Curr Osteoporos Rep 7: 64-69, 2009. 